OPEN ACCESS

Edited by:

Agustín Guerrero-Hernández, CINVESTAV, Mexico

Reviewed by:

Philip Aaronson,

King's College London, UK Antonella Naldini,

University of Siena, Italy

*Correspondence:

Bert Bosche

bert.bosche@gmail.com; boscheb@smh.ca

Specialty section:

This article was submitted to Vascular Physiology,

a section of the journal

Frontiers in Physiology

Received: 08 August 2016 Accepted: 15 November 2016 Published: 06 December 2016

Citation:

Bosche B, Molcanyi M, Rej S,

Doeppner TR, Obermann $M$, Müller DJ, Das A, Hescheler J, Macdonald RL, Noll T and Härtel FV (2016) Low-Dose Lithium Stabilizes

Human Endothelial Barrier by Decreasing MLC Phosphorylation and Universally Augments Cholinergic Vasorelaxation Capacity in a Direct

Manner. Front. Physiol. 7:593.

doi: 10.3389/fphys.2016.00593

\section{Low-Dose Lithium Stabilizes Human Endothelial Barrier by Decreasing MLC Phosphorylation and Universally Augments Cholinergic Vasorelaxation Capacity in a Direct Manner}

\author{
Bert Bosche ${ }^{1,2 *}$, Marek Molcanyi ${ }^{3,4}$, Soham Rej ${ }^{5,6}$, Thorsten R. Doeppner ${ }^{2,7}$, \\ Mark Obermann ${ }^{2,8}$, Daniel J. Müller ${ }^{9,10}$, Anupam Das ${ }^{11}$, Jürgen Hescheler ${ }^{3}$, \\ R. Loch Macdonald ${ }^{1}$, Thomas Noll ${ }^{11}$ and Frauke V. Härtel ${ }^{11}$
}

'Division of Neurosurgery, St. Michael's Hospital, Keenan Research Centre for Biomedical Science and the Li Ka Shing Knowledge Institute of St. Michael's Hospital, Department of Surgery, University of Toronto, Toronto, ON, Canada, ${ }^{2}$ Department of Neurology, University Hospital of Essen, University of Duisburg-Essen, Essen, Germany, ${ }^{3}$ Institute of Neurophysiology, Medical Faculty, University of Cologne, Cologne, Germany, ${ }^{4}$ Department of Neurosurgery, Research Unit for Experimental Neurotraumatology, Medical University Graz, Graz, Austria, ${ }^{5}$ Division of Geriatric Psychiatry, Department of Psychiatry, Sunny Brook Health Sciences Centre, University of Toronto, Toronto, ON, Canada, ${ }^{6}$ Geri-PARTy Research Group, Department of Psychiatry, Jewish General Hospital, McGill University, Montréal, QC, Canada, ${ }^{7}$ Department of Neurology, University of Göttingen Medical School, Göttingen, Germany, ${ }^{8}$ Center for Neurology, Asklepios Hospitals Schildautal, Seesen, Germany, ${ }^{9}$ Pharmacogenetics Research Clinic, Campbell Family Mental Health Research Institute, Centre for Addiction and Mental Health, Toronto, ON, Canada, ${ }^{10}$ Department of Psychiatry, University of Toronto, Toronto, ON, Canada, ${ }^{11}$ Medical Faculty Carl Gustav Carus, Institute of Physiology, Technical University of Dresden, Dresden, Germany

Lithium at serum concentrations up to $1 \mathrm{mmol} / \mathrm{L}$ has been used in patients suffering from bipolar disorder for decades and has recently been shown to reduce the risk for ischemic stroke in these patients. The risk for stroke and thromboembolism depend not only on cerebral but also on general endothelial function and health; the entire endothelium as an organ is therefore pathophysiologically relevant. Regardless, the knowledge about the direct impact of lithium on endothelial function remains poor. We conducted an experimental study using lithium as pharmacologic pretreatment for murine, porcine and human vascular endothelium. We predominantly investigated endothelial vasorelaxation capacities in addition to human basal and dynamic (thrombin-/PAR-1 receptor agonist-impaired) barrier functioning including myosin light chain (MLC) phosphorylation (MLC-P). Low-dose therapeutic lithium concentrations $(0.4 \mathrm{mmol} / \mathrm{L})$ significantly augment the cholinergic endothelium-dependent vasorelaxation capacities of cerebral and thoracic arteries, independently of central and autonomic nerve system influences. Similar concentrations of lithium $(0.2-0.4 \mathrm{mmol} / \mathrm{L})$ significantly stabilized the dynamic thrombin-induced and PAR-1 receptor agonist-induced permeability of human endothelium, while even the basal permeability appeared to be stabilized. The lithium-attenuated dynamic permeability was mediated by a reduced endothelial MLC-P known to be followed by a lessening of endothelial cell contraction and paracellular gap formation. The well-known lithium-associated inhibition of inositol monophosphatase/glycogen synthase kinase-3- $\beta$ signaling-pathways involving intracellular calcium concentrations in neurons seems to similarly occur in endothelial 
cells, too, but with different down-stream effects such as MLC-P reduction. This is the first study discovering low-dose lithium as a drug directly stabilizing human endothelium and ubiquitously augmenting cholinergic endothelium-mediated vasorelaxation. Our findings have translational and potentially clinical impact on cardiovascular and cerebrovascular disease associated with inflammation explaining why lithium can reduce, e.g., the risk for stroke. However, further clinical studies are warranted.

Keywords: bipolar disorder, blood-brain barrier, endothelial barrier, endothelial function, myosin light chain, lithium, stroke, vessel relaxation

\section{INTRODUCTION}

The mood stabilizer lithium has been successfully used in patients suffering from bipolar disorder for decades. Safe therapeutic concentrations of lithium are typically below $1 \mathrm{mmol} / \mathrm{L}$ in these patients (Geddes and Miklowitz, 2013; Yatham et al., 2013; Mohammad and Osser, 2014). In preclinical and clinical research, lithium was recognized for robust neuroprotective effects regarding various pathologic conditions (Vo et al., 2015; Doeppner et al., 2016; Vosahlikova and Svoboda, 2016). Recent studies have also identified protective effects of lithium in cardiovascular and cerebrovascular diseases (Gold et al., 2011; Chiu and Chuang, 2012). This protective effect was highlighted by two recent clinical studies demonstrating that prolonged lithium treatment reduces the risk of ischemic stroke in bipolar disorder patients (Lan et al., 2015), and improves neurological recovery after cortical stroke (Mohammadianinejad et al., 2014). Stroke and thromboembolism risk depend not only on cerebral but also on general endothelial functioning. The entire body's endothelium is therefore relevant for these pathologies. However, the impact of lithium on the endothelium and vasomotor tone and potential underlying mechanisms remain poorly understood. In light of the clinical effectiveness of lithium in stroke, we have recently examined lithium-endothelium interactions (Bosche et al., 2013, 2016). Lithium treatment (Rajkowska, 2000; Lan et al., 2015) may be effective in both ischemic and hemorrhagic stroke, and even traumatic brain injury (Leeds et al., 2014; Gao et al., 2016) by improving disturbances in endothelial functions, such as: vascular or cerebrovascular autoregulation of blood flow, vasorelaxation capacity, and dynamic endothelial barrier permeability (Bosche et al., 2003, 2009, 2010; Gündüz et al., 2003; Butcher et al., 2004; Dohmen et al., 2007; Meisel et al., 2012; Renú et al., 2015; Helbok et al., 2016).

Maintenance of intracellular calcium homeostasis in cells of the vessel wall is a prerequisite for endothelium-mediated control of vascular tone (Förstermann and Münzel, 2006; RahimzadehRofouyi et al., 2007; Bosche et al., 2009, 2010, 2016) and preservation of the endothelial barrier (Garcia et al., 1995; Bosche et al., 2013; Bosche and Macdonald, 2015), which are both determinants of the physiological endothelial function and vascular health (Yoo and Kim, 2009; Grove et al., 2015). In neurons and glia, but perhaps also in the vascular endothelium, lithium may predominantly interact with two enzymes: inositol monophosphatase (IMPase) and glycogen synthase kinase- 3 beta (GSK-3 $\beta$ ), both of which control a variety of cellular effectors involving intracellular calcium concentration $\left[\mathrm{Ca}^{2+}\right]_{\mathrm{i}}$ (Berridge, 1989, 2014; Garcia et al., 1995; Schäfer et al., 2001; Gould and Manji, 2005; Ryglewski et al., 2007; Munaron and Fiorio Pla, 2009; Trepiccione and Christensen, 2010; Bosche et al., 2013). Taken together, there is accumulating evidence indicating that lithium may have protective effects also on vessel function. On the other hand, conflicting results have been published for the impact of low lithium concentrations on vascular and endothelial functions; then human data are lacking almost completely (Bakken et al., 1992; Afsharimani et al., 2007; Rahimzadeh-Rofouyi et al., 2007; Yoo and Kim, 2009; Bosche et al., 2016). Furthermore, there is surprisingly no human data investigating whether low-dose lithium can actually improve endothelial dynamic barrier functioning. Therefore, our current experimental study fills a gap of knowledge with translational and perhaps clinical implications (Bosche and Macdonald, 2015).

Focusing on the pharmacologic interplay of low therapeutic lithium with murine, porcine and human endothelium, we hypothesized that endothelium-mediated vasomotor function may be ubiquitously improved in different species and different vascular provinces, including the cerebral one. In addition, we assume that endothelial barrier property such as the dynamic barrier of human endothelium may be stabilized and thus protected against imminent failure by low therapeutic lithium concentrations. Verifying these hypotheses may have immediate clinical impact as lithium treatment paradigms might be shifted toward broader indications in the future. To our knowledge, this is the first study proving human dynamic endothelial barrier to be stabilized by a pharmacologic treatment with low therapeutic lithium doses.

\section{MATERIALS AND METHODS}

This experimental study was approved by the University Commission on Animal Experiments with respect to the animal welfare regulations of Germany, in accordance to the European Communities Council Directive and to the National Institutes of Health (NIH) Guidelines. The study were approved by the University Ethics Committee of the Medical Faculty Carl Gustav Carus and conformed to the principles of the "Declaration of Helsinki." It was conducted under permission EZ 203112005 of the local authorities. 


\section{Murine Vessel Preparation}

The vessel grafts were isolated from murine aortas. Vessel preparation was performed according to a slightly modified method as previously described (Wilbring et al., 2013; Kopaliani et al., 2014; Bosche et al., 2016). In brief, male CD57 mice 10 weeks of age (Charles River Laboratories, Sulzfeld, Germany) were sacrificed by cutting off the upper cervical spinal cord under deep anesthesia. After death, the mice were immediately dissected. The pars thoracalis of the aorta (distal of the aortic arch) from murine aortas were recovered, explanted and directly placed into Tiprotec ${ }^{\mathrm{TM}}$ solution only (Dr F. Köhler GmbH, Bensheim, Germany), or supplemented with 0.2 or $0.4 \mathrm{mmol} / \mathrm{L}$ lithium chloride or carbonate (Sigma-Aldrich, Taufkirchen, Germany). The vessel grafts were stored at $4^{\circ} \mathrm{C}$ for $48 \mathrm{~h}$. In addition, some vessel grafts were stored at physiologic $37^{\circ} \mathrm{C}$ for $6 \mathrm{~h}$ only; these vessel grafts were incubated with $100 \mathrm{IU} / \mathrm{ml}$ Penicillin and $100 \mu \mathrm{g} / \mathrm{ml}$ Streptomycin (GIBCO Life Technologies Eggenstein, Germany) to avoid contaminations. The osmolarity of the Tiprotec ${ }^{\mathrm{TM}}$ solution was $305 \mathrm{mosmol} / \mathrm{L}$ and the $\mathrm{pH}$ 7.0, respectively. The solution contained a mixture of substances with individual concentrations shown in Table 1.

\section{Porcine Cerebral Vessel Preparation}

Cerebral vessels were taken from gyrencephalic porcine brains. The porcine cerebral vessel segments were isolated from the proximal part of the middle cerebral artery (M1 segment) from freshly slaughtered male swine (Sus domesticus, 24-26 weeks of age). Extracted vessels were collected and transported in a storage solution Tiprotec ${ }^{\mathrm{TM}}$ at $4^{\circ} \mathrm{C}$. Subsequently the isolated cerebral M1 vessel segments were flushed, cut and stored either in Tiprotec ${ }^{\mathrm{TM}}$ solution only serving as a control or Tip-rotec ${ }^{\mathrm{TM}}$ solution supplemented with $0.4 \mathrm{mmol} / \mathrm{L}$ lithium carbonate and stored at $4^{\circ} \mathrm{C}$ for at least $72 \mathrm{~h}$.

TABLE 1 | Substances of the tissue protecting solution (Tiprotec ${ }^{\mathrm{TM}}$ ) and their respective concentrations.

\begin{tabular}{ll}
\hline Substance & Concentration \\
\hline Alpha-Ketoglutarate & $2 \mathrm{mmol} / \mathrm{L}$ \\
Aspartate & $5 \mathrm{mmol} / \mathrm{L}$ \\
N-acetyl-histidine & $30 \mathrm{mmol} / \mathrm{L}$ \\
Glycine & $10 \mathrm{mmol} / \mathrm{L}$ \\
Alanine & $5 \mathrm{mmol} / \mathrm{L}$ \\
Tryptophan & $2 \mathrm{mmol} / \mathrm{L}$ \\
Sucrose & $20 \mathrm{mmol} / \mathrm{L}$ \\
Glucose & $10 \mathrm{mmol} / \mathrm{L}$ \\
Chloride & $103 \mathrm{mmol} / \mathrm{L}$ \\
Sodium & $16 \mathrm{mmol} / \mathrm{L}$ \\
Potassium & $93 \mathrm{mmol} / \mathrm{L}$ \\
Magnesium & $8 \mathrm{mmol} / \mathrm{L}$ \\
Calcium & $50 \mu \mathrm{mol} / \mathrm{L}$ \\
Deferoxamine & $82 \mu \mathrm{mol} / \mathrm{L}$ \\
LK 614 & $17 \mu \mathrm{mol} / \mathrm{L}$
\end{tabular}

\section{Choice of Specific Type of Arteria and Endothelium}

The thoracic aorta and the middle cerebral arteria were chosen as studied vessel types for two reasons. (1) The risk of stroke and in particular the risk of arterial thromboembolism is mainly based on thoracic/cervical and cerebral arteries. (2) The aorta is an elastic type artery containing both the ordinary vascular smooth muscle cells (SMC) and the myointimal SMC in a relatively high number. Furthermore, aortic endothelial cells were used in our previous vessel graft and cell culture studies regarding $\left[\mathrm{Ca}^{2+}\right]_{i}$ measurements after long-term and immediate use of lithium and its influence on the specific type of endothelial cells taken from the aorta (Schäfer et al., 2001; Bosche et al., 2013). Compared to the described aortic vessel type, cerebral arteries show different specific characteristics such as habitually missing the Windkessel function, because of having less elastic fiber, less myointimal SMC, and differently responding to certain physiological stimuli. Because of these pathophysiologic reasons, we were particularly interested to study both thoracic/cervical arteries that supply the brain as well as the specialized brain arteries including both specific types of endothelium.

\section{Isometric Force Measurement of Different Vessel Types}

Vessel function was assessed according to the method of Mulvany and Halpern (1977) as described previously (Wilbring et al., 2013; Kopaliani et al., 2014; Bosche et al., 2016). Briefly, aortic and cerebral vessel grafts $(2 \mathrm{~mm}$ in length and $0.5-0.6$ or $1.2-1.4 \mathrm{~mm}$ internal width, respectively) were transferred to carbogen equilibrated phosphate saline solution (PSS; in mmol/L: $119 \mathrm{NaCl}, 4.7 \mathrm{KCl}, 2.5 \mathrm{CaCl}_{2}, 1.17 \mathrm{MgSO}_{4}, 1.18 \mathrm{KH}_{2} \mathrm{PO}_{4}, 25$ $\mathrm{NaHCO}_{3}, 5.5$ glucose, 0.027 EDTA) and equilibrated for 30 min at $37^{\circ} \mathrm{C}$ and subsequently mounted in a myograph (DMT610 M, Power Laboratory/400; AD-Instruments, Spechbach, Germany) for isometric force measurements. The DMT tissue bath system $700 \mathrm{MO}^{\mathrm{TM}}$ in combination with PowerLab Data Acquisition System ${ }^{\mathrm{TM}}$ (AD-Instruments Spechbach, Germany) was used for data acquisition. Data recording was performed with LabChart ${ }^{\mathrm{TM}}$ software (AD-Instruments Spechbach, Germany). For maximal responses, vessels were stretched with a resting tension that was equivalent to an intraluminal pressure of $100 \mathrm{mmHg}$. After an accommodation phase of $10 \mathrm{~min}$, when a steady state tension had been reached, maximal contraction with potassium-enriched PSS solution $(124 \mathrm{mmol} / \mathrm{L} \mathrm{KCl})$ and/or 10 $\mu \mathrm{mol} / \mathrm{L}$ phenylephrine ( $\alpha 1$-adrenoceptor agonist) was recorded. After inducing a steady-state preconstriction with $10 \mu \mathrm{mol} / \mathrm{L}$ phenylephrine, concentration-response curves were determined for vessel relaxation with acetylcholine $(\mathrm{ACH})$ and sodium nitroprusside (SNP) to assess endothelium-dependent and/or endothelium-independent relaxations.

\section{Drugs Inducing Endothelium-Dependent and -Independent Relaxation Responses}

We used acetylcholine (Sigma-Aldrich) to stimulate the endothelial nitric oxide (NO) production and thereby provoked an endothelium-dependent vasodilatation. 
Sodium nitroprusside (Sigma-Aldrich) was applied to induce endothelium-independent vasodilatation by directly decreasing the vascular SMC tone. The vessels grafts were pre-contracted by using phenylephrine (Sigma-Aldrich), which induced a SMC-mediated vasoconstriction.

\section{Human Endothelial Cell Isolation and Cultivation}

Human endothelial cells were isolated from umbilical cords and cultured as described previously (Gündüz et al., 2003; Aslam et al., 2010). Briefly, the cells were cultured in PromoCell $^{\mathrm{TM}}$ endothelial cell basal medium (PromoCell, Heidelberg, Germany) supplemented with 10\% (vol/vol) fetal calf serum, $0.4 \%$ (vol/vol) endothelial growth supplement with heparin, $0.1 \mathrm{ng} / \mathrm{ml}$ human endothelial growth factor, $1.0 \mu \mathrm{g} / \mathrm{ml}$ hydrocortisone, $1 \mathrm{ng} / \mathrm{ml}$ bovine fetal growth factor, and $2 \%$ ( $\mathrm{vol} / \mathrm{vol}$ ) penicillin/streptomycin in humidified atmosphere at $37^{\circ} \mathrm{C}, 5 \% \mathrm{CO}_{2}$. Confluent monolayers were trypsinized in phosphate-buffered saline [PBS; composition in $\mathrm{mM}: 137$

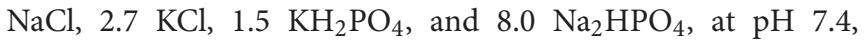
supplemented with $0.05 \%$ (wt/vol) trypsin, and $0.02 \%(\mathrm{wt} / \mathrm{vol}$ ) EDTA] and seeded at a density of $7 \times 10^{4}$ cells $/ \mathrm{cm}^{2}$ on $24 \mathrm{~mm}$ round Corning Transwell ${ }^{\mathrm{TM}}$ polycarbonate membrane filters $(0.4$ $\mu \mathrm{m})$. Four days after seeding, the experiments were performed with confluent monolayers of passage \#1.

\section{Measurement of Macromolecule Permeability of Human Endothelium}

The macromolecule permeability of endothelial cells was determined by the flux of trypan-blue labeled albumin $(60 \mu \mathrm{M})$ through the cell monolayer in a two-compartment system separated by a filter membrane as described previously (Noll et al., 1999; Gündüz et al., 2003) This albumin flux to the abluminal chamber was continuously monitored spectrophotometrically (Specord 10; Carl Zeiss). After an equilibration period of $10-15$ min thrombin was added at a final concentration of $0.2 \mathrm{U} / \mathrm{ml}$ as previously described (Aslam et al., 2010), while control cells received the same volume of solvent. In some experiments, we used (instead of thrombin) the peptide derived from the protease-activated receptor-1 (PAR1), i.e., TFLLR- $\mathrm{NH}_{2}$ (Tocris Bioscience, Bristol, UK) - a selective PAR-1 receptor agonist at a final concentration of $12 \mu \mathrm{M}$. On the other hand, comparative pre-experiments showed that mouse microvascular endothelial monolayers did not reach similarly tight permeability values in our culture model such as found for the established and well-optimized human endothelium approach. Thus, human endothelium had priority for our model.

\section{Quantification of Myosin Light Chain Phosphorylation in Human Endothelial Cells}

The myosin light chain (MLC) phosphorylation in human endothelial cells was measured by western blot analysis (Aslam et al., 2010). Therefore, cells were harvested in $2 x$ SDSPAGE sample buffer and separated by $12.5 \%$ SDS-PAGE and transferred onto nitrocellulose membranes by semidry blotting. Membranes were probed using anti-phosphoMLC-2 (Cell Signaling Technology, Danvers, MA, USA) and anti-actin (Sigma-Aldrich) in Tris-buffered saline with $0.1 \%(\mathrm{v} / \mathrm{v})$ Tween 20 and $5 \%(\mathrm{w} / \mathrm{v})$ BSA in a dilution of $1: 3000$ and 1:5000, respectively. Respective secondary HRP-conjugated anti-rabbit and anti-mouse IgG antibodies (Amersham BioSciences Buckinghamshire, UK) were used in a dilution of 1:10:000. Immunoreactivity was detected by Fusion-FX7 (PeqLab, Erlangen, Germany) with enhanced chemiluminescence and quantified by densitometric analysis by using Quantity One software (Bio-Rad, Munich, Germany). MLC phosphorylation was expressed in relation to the intracellular amount of actin.

\section{Statistical Analyses}

Results are expressed as mean \pm SEM. Confident intervals (CI) are additionally given in some experiments. Regarding the number of groups, intergroup differences were analyzed using independent-sample $t$-test according to Student, or oneway analysis of variance (ANOVA) with post-hoc Bonferroni correction for multiple comparisons of three or more groups. The general linear model for repeated measures with posthoc Bonferroni correction for multiple comparisons was performed to analyze both within subject factors over time and between group factors. $P<0.05$ was considered to be significant. Data analyses were performed using IBM SPSS (IBM, Chicago, IL, USA).

\section{RESULTS}

\section{Low Therapeutic Lithium Concentrations Augment Endothelium-Dependent but Not Endothelium-Independent Relaxation of Mouse Thoracic Arteries}

To test whether a lithium treatment at low therapeutic concentrations improves the vessel relaxation capacity, we used murine aortal vessels and $\mathrm{ACH}$ as an endothelium-dependent vasodilator besides SNP as an endothelium-independent one. Figure $1 \mathrm{~A}$ shows that a pharmacologic treatment with $0.4 \mathrm{mmol} / \mathrm{L}$ lithium chloride significantly augmented the endothelium-dependent vessel relaxation capacity of $\mathrm{ACH}$ in the dose range from $10^{-8}$ to $10^{-6.5} \mathrm{~mol} / \mathrm{L}$ compared to control. After this lithium chloride treatment the maximal $\mathrm{ACH}$-induced vessel relaxation was found at an $\mathrm{ACH}$ concentration of $10^{-6.5} \mathrm{~mol} / \mathrm{L}$ (Figure 1A). Investigations of the endothelium-independent vessel relaxation capacity using SNP are illustrated in Figure 1B. The treatment of vessels with $0.4 \mathrm{mmol} / \mathrm{L}$ lithium chloride did not significantly alter the endothelium-independent relaxation capacity compared to controls at any SNP concentration tested. Both dose response curves were found nearly congruent (Figure 1B).

Since lithium carbonate is predominantly used for clinical treatment, we then tested whether lithium carbonate may also improve the vessel relaxation capacity after stimulating with $\mathrm{ACH}$ and/or SNP, respectively. Figure 2A illustrates that 
A Endothelium-dependent vessel relaxation

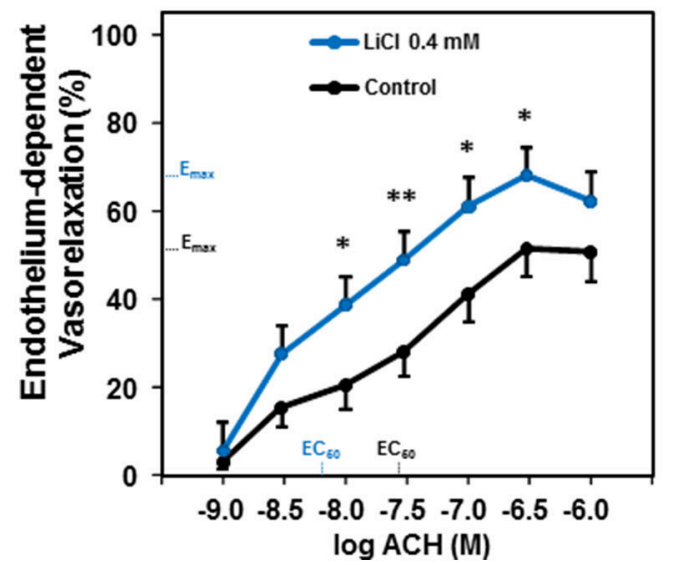

B Endothelium-independent vessel relaxation

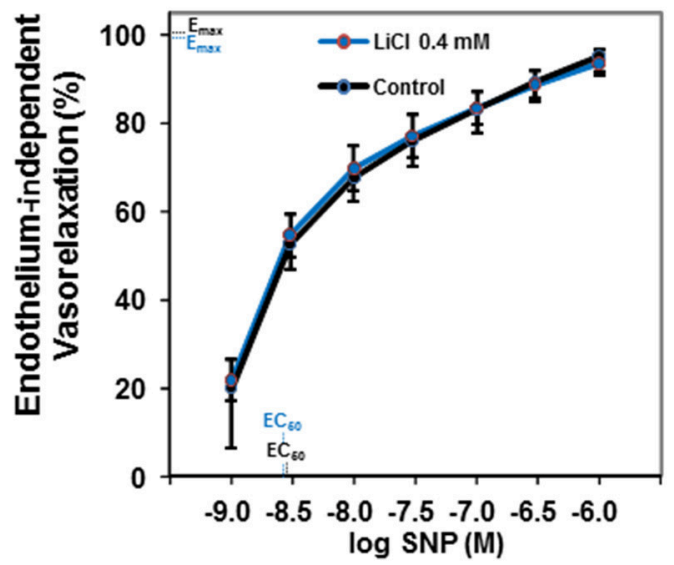

FIGURE 1 | Dose-dependent acetylcholine- and sodium nitroprusside-induced vessel relaxation and the influence of lithium on those relaxation capacities. (A) The lithium chloride pre-treated $(0.4 \mathrm{mmol} / \mathrm{L})$ murine thoracic arteries showed a significantly improved endothelium-dependent relaxation compared to control at an acetylcholine concentration range from $10^{-8}$ to $10^{-6.5} \mathrm{M}$. (B) Whereas, the lithium treatment did not significantly alter the endothelium-independent vessel relaxation at any sodium nitroprusside concentration tested. Data are shown in percent of the maximal vessel relaxation and expressed as mean \pm SEM of $n=$ 4-6 vessels per group of independent preparations, ${ }^{\star} P<0.05,{ }^{\star \star} P<0.01$ compared to control, respectively. Emax, maximal possible effect; EC 50 , half maximal effective concentration for the $\mathrm{ACH}$ respectively SNP.
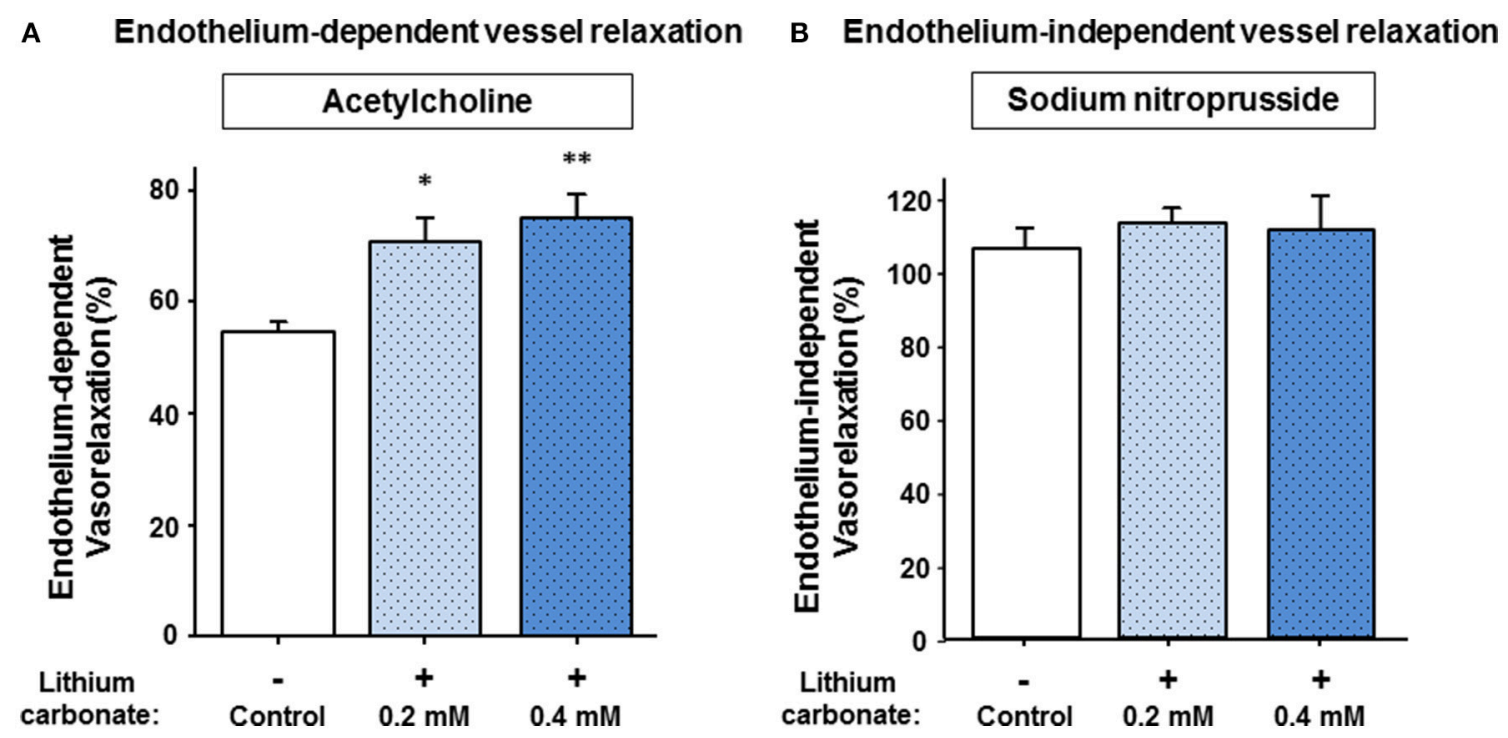

FIGURE 2 | Acetylcholine- and sodium nitroprusside-induced vessel relaxation and the influence of lithium pre-treatment on relaxation capacities. (A) The lithium carbonate pre-treated $(0.2$ and $0.4 \mathrm{mmol} / \mathrm{L})$ murine vessels showed significantly improved maximal endothelium-dependent vessel relaxation compared to control. (B) Whereas, lithium treatment did not significantly change maximal endothelium-independent vessel relaxation capacities. Data are shown as percent of the maximal vessel relaxation and expressed as mean \pm SEM of $n=4-5$ vessels per group of independent preparations, ${ }^{\star} P=0.018,{ }^{\star \star} P=0.004$ compared to control, respectively.

either a treatment with 0.2 or $0.4 \mathrm{mmol} / \mathrm{L}$ lithium carbonate significantly augmented the maximal ACH-induced vessel relaxation capacity compared to control. Thereby, the later lithium carbonate concentration $(0.4 \mathrm{mmol} / \mathrm{L})$ most sufficiently increased the relaxation capacity leading to a highly significant difference compared control (Figure 2A). Figure 2B reveals that we found neither for 0.2 nor for $0.4 \mathrm{mmol} / \mathrm{L}$ lithium carbonate a significant difference of the maximal SNP-mediated (endothelium-independent) vessel relaxation between lithium treated vessels and control. These experiments (compare Figure 2A and Figure 2B) were partly repeated following a modified protocol using a lithium pre-treatment at $37^{\circ} \mathrm{C}$ 
for $6 \mathrm{~h}$. We found similar results; lithium carbonate $(0.4$ $\mathrm{mmol} / \mathrm{L}$ ) significantly increased the maximal $\mathrm{ACH}$-induced vessel relaxation compared to control $(82.36 \pm 2.36 \%$ vs. 52.94 $\pm 5.52 \%, n=4-5$ per group, $P=0.003)$. Whereas, the SNPinduced vessel relaxation was not significantly altered by lithium carbonate $(105.09 \pm 4.08 \%$ vs. $102.63 \pm 1.04 \%, n=5$ per group, $P=0.583$, n.s.); similar (non-significantly altered) results were found when submaximal SNP concentrations (e.g., $10^{-8.5} \mathrm{mM}$ ) were used for vasodilatation with or without $0.4 \mathrm{mmol} / \mathrm{L}$ lithium carbonate pre-treatment $(80.15 \pm 6.45 \%$ vs. $81.01 \pm 13.82 \%, n=$ 5 per group, $P=0.902$, n.s).

\section{Low Therapeutic Lithium Concentrations Improve Endothelium-Dependent Relaxation of Cerebral Arteries}

To test whether low lithium concentrations also augment the endothelium-dependent relaxation capacity of cerebral vessels from gyrencephalic brains, we performed another set of experiments using porcine M1 segments of the middle cerebral arteries (MCA) and lithium carbonate treatment. Cerebral vessels of good to excellent functions (e.g., constriction force $\geq 8 \mathrm{mN} / \mathrm{mm}$ for $34 \mathrm{mM}\left[\mathrm{K}^{+}\right]_{\mathrm{e}}$, a representative example is given in Figure 3A) were used for these lithium pretreated $\mathrm{ACH}$-induced vasorelaxation experiments. Figure 3B illustrates that $0.4 \mathrm{mmol} / \mathrm{L}$ lithium carbonate significantly augmented the endothelium-dependent cerebral vessel relaxation in response to $10^{-6.5} \mathrm{~mol} / \mathrm{L} \mathrm{ACH}$ (at a mechanical pre-dilatation/constriction equal to a vessel lumen pressure of $100 \mathrm{mmHg}$ ) compared to control. These findings of porcine cerebral and thoracic vessels indicated lithium (at low therapeutic concentrations) as an agent equally augmenting endothelium-mediated relaxation capacities of different vascular provinces and species in a direct manner (i.e., not via central and autonomic nervous system-associated routes).

\section{Low Therapeutic Lithium Concentrations Appear to Reduce Resting Human Endothelial Permeability}

The universally positive influence of low lithium concentrations on the endothelium-dependent vessel relaxation capacity prompted us to further investigate, whether other endothelium functions could also be modified or improved by pharmacological lithium treatment at low therapeutic concentrations. Translationally, we were most interested in human endothelial functions such as endothelium permeability/impermeability. Therefore, we scrutinized the basal permeability of human endothelial monolayers (passage $\# 1$ ), but also the dynamic hyper-permeability induced by thrombin (see below). We continuously accessed the albumin turnover of the monolayers in a resting state that were treated with 0 (control) and $0.4 \mathrm{mmol} / \mathrm{L}$ lithium. Over the entire observation period of $120 \mathrm{~min}$, the basal permeability of lithium treated human endothelial monolayers was lower compared to control (Figure 4A). This was, however, only reflected by strong statistical trends comparing the values (e.g., after $40 \mathrm{~min}, n=$ 4-6 per group, $P=0.076$ ) or the integrals, i.e., areas under
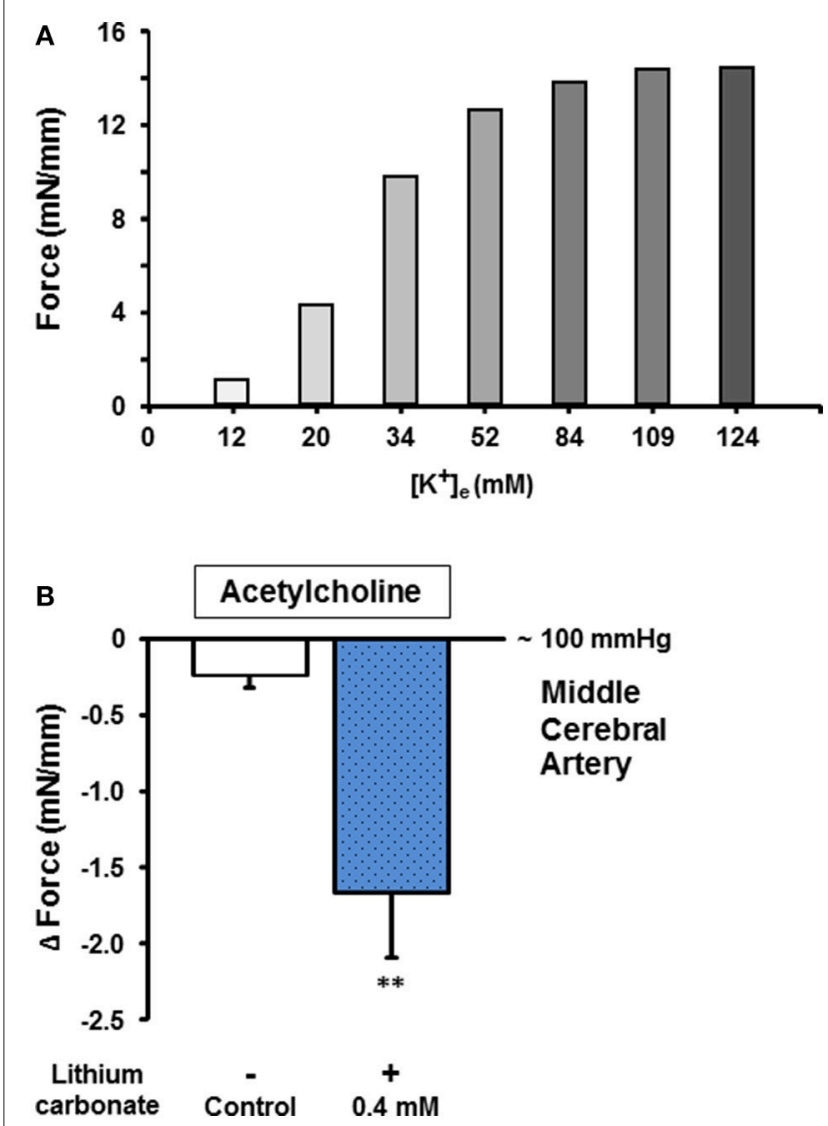

FIGURE 3 | Endothelium-dependent cholinergic vessel function and the influence of lithium carbonate on the relaxation capacity of cerebral arteries. (A) Representative pre-assessment of physiologic vessel functions (e.g., potassium-induced constriction force $[\mathrm{mN} / \mathrm{mm}]$ ) for further relaxation capacity measurements. (B) The lithium carbonate $(0.4 \mathrm{mmol} / \mathrm{L})$ pre-treated porcine middle cerebral arteries showed significantly improved endothelium-dependent vessel relaxation compared to control. Data are shown as $\Delta \mathrm{mN} / \mathrm{mm}$ and expressed as mean \pm SEM of $n=3-4$ vessels per group of independent preparations, ${ }^{* \star} P=0.006$ compared to control.

the curve of permeability to control (AUC, $n=4-6$ per group, $P=0.064$, n.s., Figure 4B).

\section{Low Therapeutic Lithium Concentrations Significantly Abolish Human Dynamic Endothelial Hyper-Permeability}

Since thrombin plays a relevant pathophysiologic role for the endothelial barrier failure or impairment (Coughlin, 2000), e.g., during and after cerebral ischemia and hemorrhages (Stokum et al., 2016), we investigated the impact of lithium treatment on the thrombin-induced hyper-permeability of human endothelium. Regarding the basal permeability before thrombin addition, we again found similarly strong trends between lithium 0.2 , respectively, $0.4 \mathrm{mmol} / \mathrm{L}$ treated endothelium and control $[0.4156 \pm 0.0253$, respectively $0.5189 \pm 0.0714$ vs. $0.8315 \pm 0.1491\left(\times 10^{6} \mathrm{~cm} / \mathrm{s}\right), n=4-6$ per group, $P=$ 0.070 and $P=0.095$, both n.s.]. Figure 5A illustrates that thrombin significantly increased the endothelial permeability 


\section{A}

Basal permeability of human endothelium

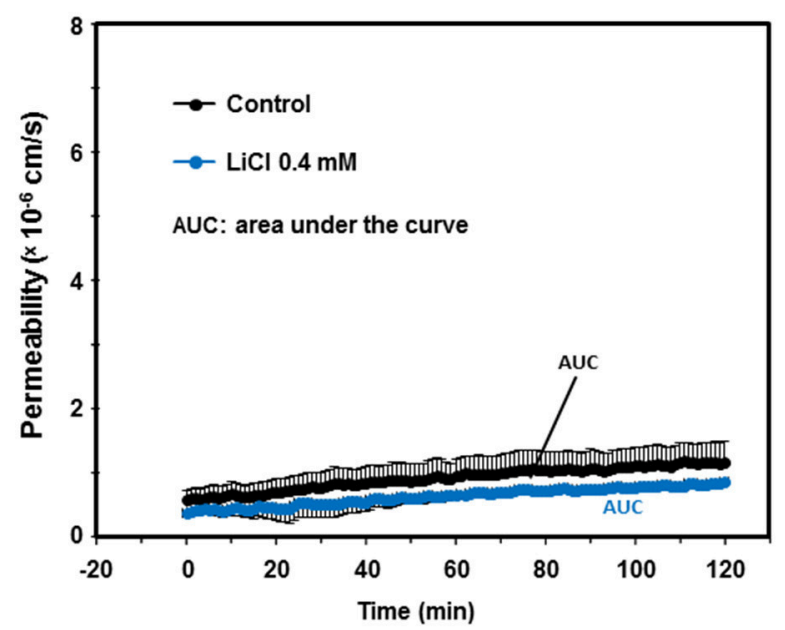

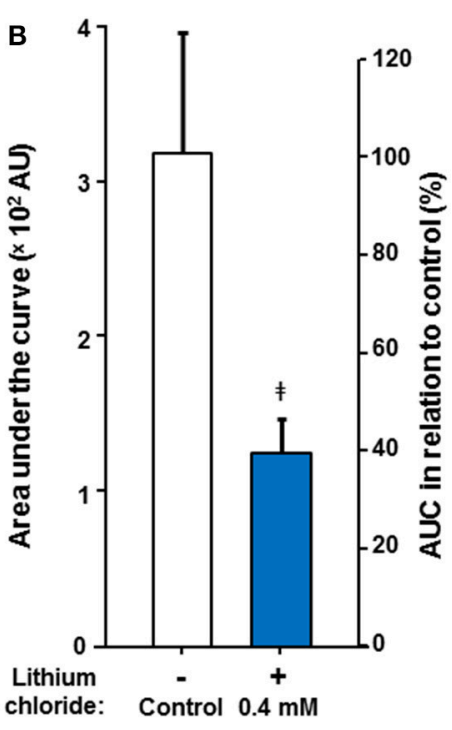

FIGURE 4 | Effect of lithium at low therapeutic concentrations on the basal permeability of human endothelium. Confluent human endothelial monolayers were exposed to different concentrations of lithium for $\mathbf{4 8} \mathbf{h}$. (A) Basal albumin permeability is shown after pre-treating with Tiprotec ${ }^{\mathrm{TM}}$ solution in absence of lithium as control (--) or with the same solution containing $0.4 \mathrm{mmol} / \mathrm{L}$ lithium (-- - ). Over the entire observation period, the lithium pre-treated endothelial monolayers showed a lower permeability (i.e., a tighter basal barrier function). Differences were reflected by strong statistical trends at certain time points (see Result Section); AUC, areas under the curve. (B) By comparing the integrals, i.e., AUC (compare part A) of permeability assessments as a single measure for $120 \mathrm{~min}$, the barrier built by the lithium treated human endothelium appears to be tighter compared to control $\left({ }^{\ddagger} P=0.064\right.$, not significant [n.s.]). Data are expressed as mean \pm SEM of $n=4-6$ separate experiments per group of independent cell preparations.

of all groups in a transient way (all, $P<0.001$, respectively, Table 2). More importantly, Figure 5 shows that the treatment with lithium chloride $(0.4$ and $0.2 \mathrm{mmol} / \mathrm{L})$ significantly reduced the permeability/hyper-permeability $(P=0.004$ and $P<0.001$, respectively); Table 3 summarizes mean differences with the respective statistics in detail. Correspondingly, hyperpermeability expressed as AUC was significantly lower in human endothelium treated with 0.4 and $0.2 \mathrm{mmol} / \mathrm{L}$ lithium compared to control (AUC, $n=4-6$ per group, $P=0.019$ and $P=0.003$, respectively, Figure 5B).

To investigate the hypothesis whether the lithiumattenuated dynamic hyper-permeability of human endothelium was mediated by an involvement of the receptor PAR-1 and downstream signaling, we repeated the experiments (compare Figure 5A) using the selective PAR-1 receptor agonist TFLLR- $\mathrm{NH}_{2}$. Lithium chloride $(0.2$ and $0.4 \mathrm{mmol} / \mathrm{L})$ likewise significantly abolished the TFLLR-NH $\mathrm{N}_{2}$-induced hyper-permeability (Figure 6).

\section{Lithium-Attenuated Human Dynamic Endothelial Permeability Is Mediated by a Reduced Endothelial Myosin Light Chain Phosphorylation}

The endothelial MLC phosphorylation is regulated by the protein kinase $\mathrm{C}$ and chiefly controls the contractile apparatus of endothelial cells (Garcia et al., 1995). Due to this phosphorylation the active contractile apparatus $\left[\mathrm{Ca}^{2+}\right]_{\mathrm{i}}$-dependently develops small paracellular gaps and thus hyper-permeability (Aslam et al., 2010). Lithium is known to inhibit the inositol monophosphatase/glycogen synthase kinase-3- $\beta$ signalingpathways including $\left[\mathrm{Ca}^{2+}\right]_{i}$ in neurons and perhaps other cells (Berridge, 1989, 2014; de Sousa et al., 2015; Bosche et al., 2016). These down-steam pathways may affect MLC phosphorylation; we therefore studied the MLC phosphorylation (with or without lithium) as possible link to endothelial permeability. Figure 7 demonstrates that a prolonged lithium treatment significantly reduced the endothelial intracellular MLC phosphorylation during thrombin-induced hyper-permeable conditions compared to control $[1.75 \pm 0.26$ vs. $3.20 \pm 0.23$ (ratio of MLC-P/actin) $n=3$ per group, $P=0.014$ ] suggesting a potential mechanism of the lithium-attenuated dynamic permeability of human endothelium.

\section{DISCUSSION}

We conducted an experimental study using lithium as a pharmacologic treatment for murine, porcine and human vascular endothelium with three interrelated goals. First, we wanted to clarify whether low concentrations of lithium help support endothelium-dependent vessel relaxation, since conflicting results had previously been published (Bakken et al., 1992; Afsharimani et al., 2007; Rahimzadeh-Rofouyi et al., 2007; Bosche et al., 2016). Second, we wanted to assess whether low concentrations of lithium carbonate, as a commonly used drug in bipolar disorder and other psychiatric/neurological conditions (Geddes and Miklowitz, 2013; Yatham et al., 2013), correspondingly augment endothelium-dependent thoracic and 
A Dynamic (hyper-)permeability of human endothelium

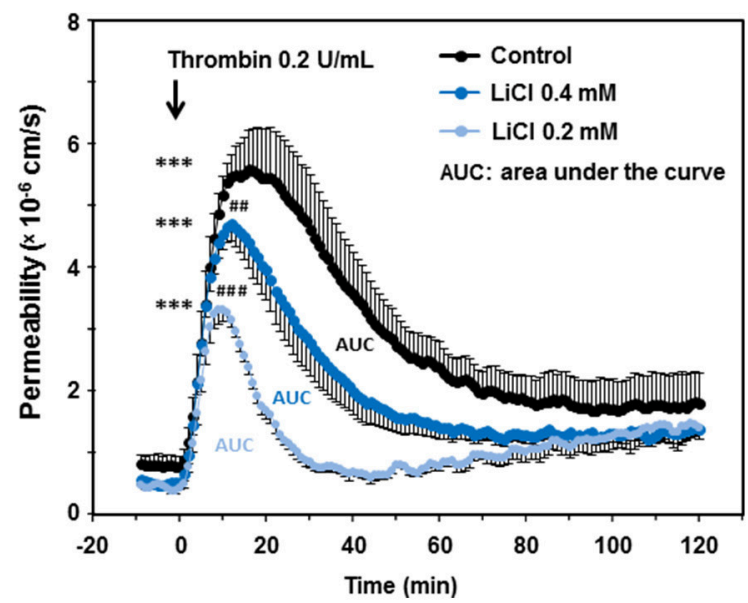

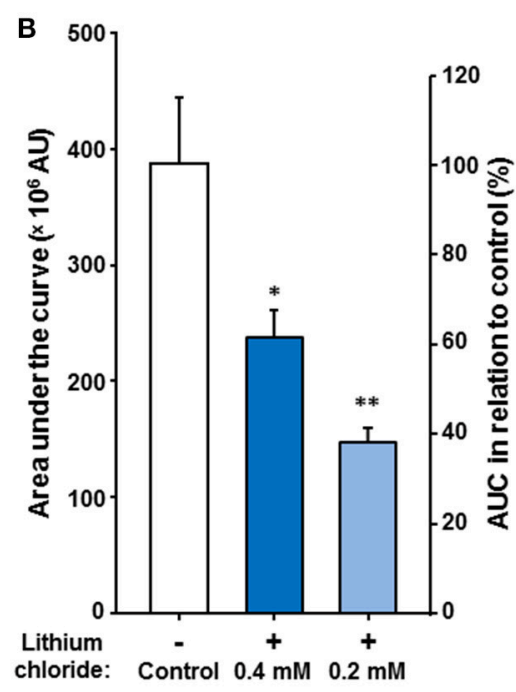

FIGURE 5 | Effect of lithium at low therapeutic concentrations on the dynamic, thrombin-induced hyper-permeability of human endothelium. Confluent human endothelial monolayers were exposed to lithium for $48 \mathrm{~h}$. (A) Basal and dynamic, thrombin-induced hyper-permeability after pretreating with Tiprotec ${ }^{\mathrm{TM}}$

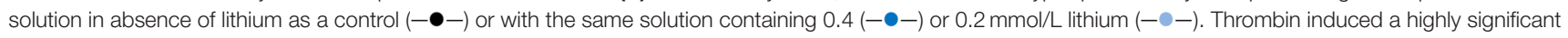
increase in permeability of control and both lithium treated groups (all, ${ }^{\star \star \star} P<0.001$ compared to their basal permeability, respectively). Before addition of thrombin the basal albumin permeability of 0.4 and $0.2 \mathrm{mmol} / \mathrm{L}$ lithium treated human monolayers was slightly but non-significantly lower compared to control $(P=0.095$ and $P=$ 0.070 , n.s., respectively). Both types of lithium treated human endothelium showed a significantly lower dynamic thrombin-induced hyper-permeability compared to control (\#\#P = 0.004 and \#\#\#P < 0.001, respectively; see also Table 3 for further details). (B) Consistently, the dynamic hyper-permeability of lithium treated endothelium ( 0.4 and $0.2 \mathrm{mmol} / \mathrm{L}$, integrals/AUC, compare part $\mathbf{A})$ was significantly lower compared to control $\left({ }^{\star} P=0.019\right.$ and ${ }^{* \star} P=0.003$, respectively). Data are expressed as mean \pm SEM of $n=4-6$ separate experiments per group of independent cell preparations.

TABLE 2 | Permeability increase (basal to peak) of human endothelium after treatment with different lithium concentrations.

\begin{tabular}{|c|c|c|c|}
\hline Group & Mean increase $\left(10^{6} \times \mathrm{cm} / \mathrm{s}\right)$ & SEM & $P$-value \\
\hline Control & 5.3962 & \pm 0.4043 & $<0.001$ \\
\hline Lithium $0.2 \mathrm{mmol} / \mathrm{L}$ & 2.9419 & \pm 0.1747 & $<0.001$ \\
\hline Lithium $0.4 \mathrm{mmol} / \mathrm{L}$ & 3.9716 & \pm 0.3881 & $<0.001$ \\
\hline
\end{tabular}

cerebral vessel relaxation capacity. Third and most important, we aimed to find similar evidence as to whether low lithium concentrations can improve other endothelial functions such as the basal and dynamic permeability (Coughlin, 2000; Gündüz et al., 2003; Aslam et al., 2010; Bosche et al., 2013) particularly of human endothelium (Gündüz et al., 2015). Moreover, we wanted to provide some first hints for a mechanistic explanation of the findings; and modified MLC-P appeared to be a possible candidate.

It is worth to mention that models with denervated vessels were performed to investigate the isolated vessel reaction in direct response to different concentrations of a pharmacologic lithium treatment independently of the influence of lithium on the central and hence the vegetative nerve system including its remote control of the vessel tones.

The data presented here suggested that lithium improved and stabilized endothelium-dependent vascular relaxation capacity and the human endothelial dynamic barrier, respectively. The latter represents a unique finding for human endothelium.
After pharmacologic treatment with lithium carbonate at low therapeutic concentrations (up to $0.4 \mathrm{mmol} / \mathrm{L}$ ), arterial relaxation capacities were significantly improved in different vascular provinces. This means that the improvement was similarly mediated through both aortal and cerebral endothelium. An endothelium-independent mechanism was not involved, in concordance with previous reports showing that removal of the endothelium hindered the lithium-augmented vasorelaxation (Bosche et al., 2016). Moreover, the endothelium-independent NO donor effect (induced by SNP) remained unaltered by lithium again shifting endothelium as a lithium target into focus. The findings of lithium carbonate also originated from two different vertebrate species (mouse and swine) and additionally different vascular provinces suggesting a general rather than a locally circumscriptive endothelial characteristic. We then followed up those experiments, by investigating endothelium isolated from human vessels. The impact of low therapeutic lithium on dynamic endothelial barrier functioning was directly measured for human endothelium and represented a novel finding determining lithium to significantly stabilize endothelial barrier. These findings underline the concept of lithium being a promising approach of targeting human endothelium for treating (or at least positively influencing) vascular and cerebrovascular dysfunctions such as impaired autoregulation and endothelial barrier breakdown, as found after cerebral ischemia (Bosche et al., 2003; Dohmen et al., 2007; Wijdicks et al., 2014) or hemorrhagic stroke such as subarachnoid hemorrhage (Bosche et al., 2009, 
TABLE 3 | Comparison of the dynamic thrombin-induced hyper-permeability of groups of human endothelium treated with or without lithium.

\begin{tabular}{|c|c|c|c|c|c|c|}
\hline \multicolumn{2}{|c|}{ Group comparison } & \multirow[t]{2}{*}{ Mean difference $\left(10^{6} \times \mathrm{cm} / \mathrm{s}\right)$} & \multirow[t]{2}{*}{ SEM } & \multirow[t]{2}{*}{$P$-value } & \multicolumn{2}{|c|}{$95 \% \mathrm{Cl}$} \\
\hline & & & & & LB & UB \\
\hline Control & Lithium 0.2 mmol/L & 1.6430 & \pm 0.3351 & $<0.001$ & 0.7533 & 2.5327 \\
\hline Control & Lithium 0.4 mmol/L & 1.0248 & \pm 0.2681 & 0.004 & 0.3130 & 1.7366 \\
\hline Lithium 0.4 mmol/L & Lithium 0.2 mmol/L & 0.6182 & \pm 0.0307 & 0.181 & -0.1972 & 11.4337 \\
\hline
\end{tabular}

Cl, confidence interval; LB, lower bound; UB, upper bound.

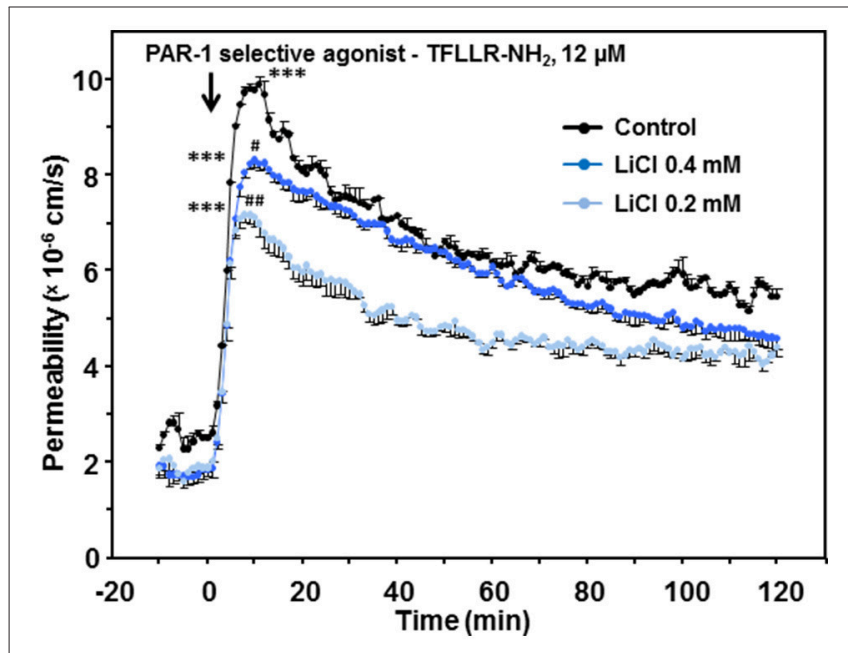

FIGURE 6 | Effect of lithium at low therapeutic concentrations on the dynamic, TFLLR- $\mathrm{NH}_{2}$-induced hyper-permeability of human endothelium. TFLLR-NH 2 is an oligopeptide (Thr-Phe-Leu-Leu-Arg- $\mathrm{NH}_{2}$ ), which acts as a PAR-1 selective agonist. Confluent human endothelial monolayers were exposed to different concentrations of lithium for $48 \mathrm{~h}$. Basal and dynamic TFLLR-NH $\mathrm{N}_{2}$-induced hyper-permeability after pretreating with Tiprotec $^{\mathrm{TM}}$ solution in absence of lithium as a control (--) or with the same

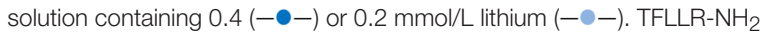
induced a highly significant increase in permeability of control and both lithium treated groups (all, ${ }^{* \star *} P<0.001$ compared to their basal permeability, respectively). Both types of lithium treated human endothelium revealed a significantly lower dynamic TFLLR-NH $\mathrm{N}_{2}$-induced hyper-permeability compared to control ( $\# P=0.031$ and $\# \# P=0.001$, respectively). Data are expressed as mean \pm SEM of $n=3$ separate experiments per group of independent cell preparations.

2010; Urday et al., 2015). Predominantly, post-ischemic malignant brain edema after hemispheric stroke (Hacke et al., 1996; Bosche et al., 2003) may represent a potential field (Wijdicks et al., 2014) for a pharmacologic treatment with lithium. However, further studies and particularly clinical investigations will be required to provide more definitive conclusions.

The question arises as to how lithium improves endothelial functioning. Similarly to neurons and glia, lithium also intracellularly interacts with IMPase and GSK-3 $\beta$ in vascular endothelium subsequently altering $\mathrm{IP}_{3}, \mathrm{cAMP}$ and thus $\left[\mathrm{Ca}^{2+}\right]_{\mathrm{i}}$ (Berridge, 1989, 2014; Schäfer et al., 2001; Gould and Manji, 2005; Ryglewski et al., 2007; Munaron and Fiorio Pla, 2009; Trepiccione and Christensen, 2010; Bosche et al., 2013). In endothelial cells, lithium prevents the discharge of calcium from endogenous storage by inhibition of the inositol trisphosphate $\left(\mathrm{IP}_{3}\right)$-sensitive calcium channels of the endothelial endoplasmic reticulum (ER), thus counteracting cells stress-induced cytosolic calcium increase and conferring lithium an endothelial cytoprotective potential (Schäfer et al., 2001; Bosche et al., 2013). Functionally, maintenance of $\left[\mathrm{Ca}^{2+}\right]_{\mathrm{i}}$ homeostasis at low-dose lithium may manifest as modified endothelium-mediated vasodilation (Förstermann and Münzel, 2006; RahimzadehRofouyi et al., 2007; Bosche et al., 2016) but also as preserved dynamic endothelial barrier function. Besides the effect of lithium on $\mathrm{IP}_{3}$-sensitive $\left[\mathrm{Ca}^{2+}\right]_{\mathrm{i}}$ (Berridge, 1989) particularly in endothelial cells previously reported by our group (Schäfer et al., 2001; Bosche et al., 2013), nitric oxide (Bosche et al., 2016), and MLC phosphorylation (Aslam et al., 2010) may serve as downstream targets mediating vasorelaxation and endothelial contraction inducing hyper-permeability, respectively (for review see Stokum et al., 2016). In endothelium, the MLC-P is protein kinase $\mathrm{C}$ and $\left[\mathrm{Ca}^{2+}\right]_{\mathrm{i}} /$ calmodulin-dependent (Garcia et al., 1995; Aslam et al., 2010). By identifying the reduced endothelial MLC phosphorylation after prolonged low-dose lithium treatment, we found a mechanistic explanation for the lithium-attenuated endothelial hyper-permeability and slightly reduced basal permeability. Characterizing the detailed endothelial mechanisms should be the next step for our future research perhaps additionally in an in-vivo model. If MLC-P may also be influenced by lithium in vascular SMCs is perhaps likely but unclear, yet, and thus requires also further research.

In light of our current findings, lithium at low therapeutic concentrations functionally represented a universal endothelium protective agent, as reported by others in single species and only one vascular province (Bakken et al., 1992; Afsharimani et al., 2007; Rahimzadeh-Rofouyi et al., 2007). The last of these studies, e.g., found that low lithium concentrations $(0.5 \mathrm{mmol} / \mathrm{L})$ reduced and higher ones $(2 \mathrm{mmol} / \mathrm{L})$ improved $\mathrm{ACH}$-induced mesenteric vascular bed relaxation, which is partly at odds with our results, perhaps because of the mesenteric vessel type used (Rahimzadeh-Rofouyi et al., 2007). We investigated thoracic and middle cerebral arteries. Relaxation of cerebral vessels during and after an ischemia/reperfusion leads to collateral cerebral blood flow, and thus characterizes an intrinsic strategy of the cerebral vasculature to protect neuroglial structures but also vasculature including endothelium against ischemic injury (Heiss et al., 2001), likewise reported for the heart (Koerselman et al., 2003; Meier et al., 2013). Indeed, cerebral collateral status and sufficiently enlarged calibers of collateral arteries 


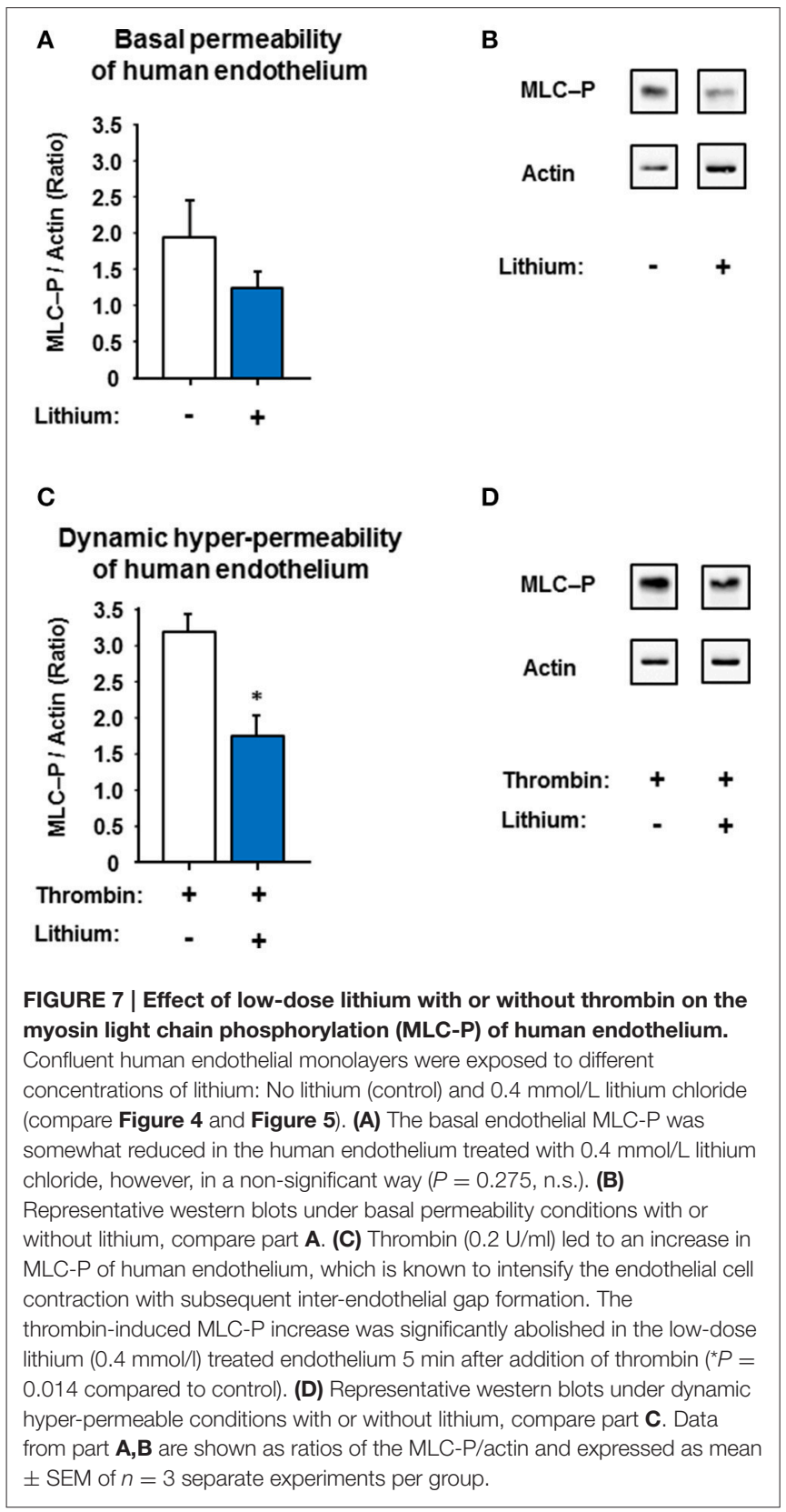

have recently been identified as most relevant for final infarct volume, vasogenic edema formation (with subsequent midline shift), and hence patient outcome (Volny et al., 2016; van den Wijngaard et al., 2016; van der Hoeven et al., 2016). Therefore, patients at risk for stroke with unfortunate collateral status (thus portending poor outcome) could particularly profit from a lithium treatment at low concentrations via a generally improved endothelium-dependent vessel relaxation capacity. This might be speculative, but on the other hand, the lithium-augmented cerebrovascular relaxation capacity may party explain, why continuous lithium treatment can reduce the risk for stroke (Lan et al., 2015) or may improve neurologic recovery after cortical stroke (Mohammadianinejad et al., 2014) potentially caused by various beneficiary effects on neurons (Doeppner et al.,
2016; Vosahlikova and Svoboda, 2016), or platelets (Barry et al., 2003) including the direct ones on vascular and cerebrovascular endothelium (Afsharimani et al., 2007; Rahimzadeh-Rofouyi et al., 2007; Bosche et al., 2013, 2016), as presented here. Directly or secondarily impaired endothelial barrier after ischemia and hemorrhages followed by vasogenic edema formation (Stokum et al., 2016) were known to be highly relevant for clinical outcome of various types of stroke (Hacke et al., 1996; Bosche et al., 2003; Macdonald, 2014; Wijdicks et al., 2014; Urday et al., 2015). Therefore, those patients may clinically benefit from a lithium-stabilized, MLC-mediated dynamic endothelial barrier with subsequently reduced vasogenic edema formation. However, additional research is warranted, which will help to better understand the complex phenomenon of lithiumstrengthened endothelial barrier and augmented cerbrovascualar relaxation capacities including the potential benefit for stroke patients.

Three limitation of our study deserve mentioning. First, the endothelial intracellular lithium concentration was not directly measured, e.g., by using lithium NMR spectroscopy methods (Fonseca et al., 2004), in our study. On the other hand, serum levels of lithium and not intracellular concentrations are clinically relevant and used for lithium therapy monitoring. Second, a complete mechanistic explanation for all lithiumassociated endothelial findings is not yet given in this paper. The known effects of lithium on neurons, particularly on neuronal GSK-3 $\beta$ /IMPase pathways are a matter of extensive research over decades; however, exploring the direct lithiumendothelium interaction has just recently started. Thus, our knowledge is still limited and further research is needed and planed in this field. Third, an ideal model for human endothelial barrier respectively blood-brain barrier does not yet exist (Helms et al., 2016). For investigating (fairly tight) endothelial permeability, we used human endothelial cells of passage \#1, aiming to avoid culture effects due to higher passages. Using human cerebral endothelial cells might further improve our particular knowledge about lithium in cerebrovascular diseases. However, commercially available human endothelial cell lines are immortalized and hence of higher passages with many pitfalls restricting translations to the in-vivo situation. Hence our approach represents a compromise minimizing some but not all methodologic drawbacks.

In conclusion, a low-dose therapeutic concentration of the mood stabilizer lithium directly stabilizes the human endothelial barrier by reducing MLC phosphorylation weakening the endothelial contractile machinery and thus avoiding paracellular gap formation. Moreover, low-dose lithium augments endothelium-dependent thoracic and cerebral vasorelaxation capacity. These findings of improved endothelial functions could partly explain why long-term lithium treatment reduces the risk for ischemic stroke in patients who receive lithium. Therefore, our results may open a gate for novel lithium indications potentially for patients suffering primarily from cardiovascular and cerebrovascular diseases with impending or already impaired endothelial functions. However, further translational research and clinical studies are warranted. 


\section{AUTHOR CONTRIBUTIONS}

All listed authors substantially contributed to this work. BB, $\mathrm{MM}, \mathrm{FH}$, and TN designed the study. $\mathrm{BB}, \mathrm{MM}$, and $\mathrm{FH}$ performed the experiments and acquired the data, which $\mathrm{BB}, \mathrm{MM}, \mathrm{SR}, \mathrm{JH}, \mathrm{RM}, \mathrm{AD}, \mathrm{TN}$, and $\mathrm{FH}$ analyzed. $\mathrm{BB}$, $\mathrm{SR}, \mathrm{TD}, \mathrm{MO}, \mathrm{DM}, \mathrm{TN}$, and $\mathrm{FH}$ wrote the manuscript; all authors reviewed, critically revised, and approved it for final publication. TN and $\mathrm{FH}$ contributed equally to this work.

\section{REFERENCES}

Afsharimani, B., Moezi, L., Sadeghipour, H., Rahimzadeh-Rofouyi, B., Nobakht, M., Sanatkar, M., et al. (2007). Effect of chronic lithium administration on endothelium-dependent relaxation of rat mesenteric bed: role of nitric oxide. Can. J. Physiol. Pharmacol. 85, 1038-1046. doi: 10.1139/Y07-095

Aslam, M., Härtel, F. V., Arshad, M., Gündüz, D., Abdallah, Y., Sauer, H., et al. (2010). cAMP/PKA antagonizes thrombin-induced inactivation of endothelial myosin light chain phosphatase: role of CPI-17. Cardiovasc. Res. 87, 375-384. doi: $10.1093 / \mathrm{cvr} / \mathrm{cvq} 065$

Bakken, I. J., Vincent, M. B., White, L. R., Cappelen, J., Skaanes, K. O., and Sjaastad, O. (1992). Low concentrations of lithium and cyclooxygenase inhibitors enhance endothelin-1 (ET-1)-induced contractions in human temporal artery, but not in porcine ophthalmic artery. Headache 32, 475-479. doi: 10.1111/j.1526-4610.1992.hed3210475.x

Barry, F. A., Graham, G. J., Fry, M. J., and Gibbins, J. M. (2003). Regulation of glycogen synthase kinase 3 in human platelets: a possible role in platelet function? FEBS Lett. 553, 173-178. doi: 10.1016/S0014-5793(03)01015-9

Berridge, M. J. (1989). The albert lasker medical awards. Inositol trisphosphate, calcium, lithium, and cell signaling. JAMA 262, 1834-1841. doi: 10.1001/jama. 1989.03430130110043

Berridge, M. J. (2014). Calcium signalling and psychiatric disease: bipolar disorder and schizophrenia. Cell Tissue Res. 357, 477-492. doi: 10.1007/s00441-0141806-Z

Bosche, B., Dohmen, C., Graf, R., Neveling, M., Staub, F., Kracht, L., et al. (2003). Extracellular concentrations of non-transmitter amino acids in peri-infarct tissue of patients predict malignant middle cerebral artery infarction. Stroke 34, 2908-2913. doi: 10.1161/01.STR.0000100158.51986.EB

Bosche, B., Graf, R., Ernestus, R. I., Dohmen, C., Reithmeier, T., Brinker, G., et al. (2009). "Clusters of cortical spreading depolarizations after subarachnoid hemorrhage may advance delayed cortical ischemia via reduced O2-supply and increased O2-consumption," in Brain and BrainPET 2009 - XXIVth Congress of the ISCBF\&M (Chicago IL).

Bosche, B., Graf, R., Ernestus, R. I., Dohmen, C., Reithmeier, T., Brinker, G., et al. (2010). Recurrent spreading depolarizations after subarachnoid hemorrhage decreases oxygen availability in human cerebral cortex. Ann. Neurol. 67, 607-617. doi: 10.1002/ana.21943

Bosche, B., and Macdonald, R. L. (2015). Letter by Bosche and Macdonald regarding article, "relevance of blood-brain barrier disruption after endovascular treatment of ischemic stroke: dual-energy computed tomographic study/Large, Rapid, Reperfusion, all is too simple: call for novel strategies on neurovascular unit/blood-brain barrier protection." Stroke 46, e126-e127. doi: 10.1161/STROKEAHA.115.009131

Bosche, B., Molcanyi, M., Noll, T., Rej, S., Zatschler, B., Doeppner, T. R., et al. (2016). A differential impact of lithium on endothelium-dependent but not on endothelium-independent vessel relaxation. Prog. Neuropsychopharmacol. Biol. Psychiatry 67, 98-106. doi: 10.1016/j.pnpbp.2016.02.004

Bosche, B., Schäfer, M., Graf, R., Härtel, F. V., Schäfer, U., and Noll, T. (2013). Lithium prevents early cytosolic calcium increase and secondary injurious calcium overload in glycolytically inhibited endothelial cells. Biochem. Biophys. Res. Commun. 434, 268-272. doi: 10.1016/j.bbrc.2013.03.047

Butcher, K. S., Baird, T., MacGregor, L., Desmond, P., Tress, B., and Davis, S. (2004). Perihematomal edema in primary intracerebral hemorrhage is

\section{ACKNOWLEDGMENTS}

This study was supported by grants of the Deutsche Forschungsgemeinschaft (DFG) to BB (BO 4229/1-1, BO 4229/2-1, Novel strategies to protect the neurovascular unit). We gratefully acknowledge the technical support by A. Messer, B. Müller, and B. Zatschler as well as the statistical advices by Dr. H. Stützer emeritus member of the Institute of Medical Statistics, Informatics and Epidemiology (IMSIE) of the University of Cologne.

plasma derived. Stroke 35, 1879-1885. doi: 10.1161/01.STR.0000131807. 54742.1a

Chiu, C. T., and Chuang, D. M. (2012). Neuroprotective action of lithium in disorders of the central nervous system. Zhong Nan Da Xue Xue Bao Yi Xue Ban 36, 461-476. doi: 10.3969/j.issn.1672-7347.2011.06.001

Coughlin, S. R. (2000). Thrombin signalling and protease-activated receptors. Nature 14, 258-264. doi: 10.1038/35025229

de Sousa, R. T., Zanetti, M. V., Talib, L. L., Serpa, M. H., Chaim, T. M., Carvalho, A. F., et al. (2015). Lithium increases platelet serine- 9 phosphorylated GSK-3 $\beta$ levels in drug-free bipolar disorder during depressive episodes. J. Psychiatr. Res. 62, 78-83. doi: 10.1016/j.jpsychires.2015.01.016

Doeppner, T. R., Kaltwasser, B., Sanchez-Mendoza, E. H., Caglayan, A. B., Bähr, M., and Hermann, D. M. (2016). Lithium-induced neuroprotection in stroke involves increased miR-124 expression, reduced RE1-silencing transcription factor abundance and decreased protein deubiquitination by GSK3 $\beta$ inhibition-independent pathways. J. Cereb. Blood Flow Metab. doi: 10.1177/0271678X16647738. [Epub ahead of print].

Dohmen, C., Bosche, B., Graf, R., Reithmeier, T., Ernestus, R. I., Brinker, G., et al. (2007). Identification and clinical impact of impaired cerebrovascular autoregulation in patients with malignant middle cerebral artery infarction. Stroke 38, 56-61. doi: 10.1161/01.STR.0000251642.18522.b6

Fonseca, C. P., Montezinho, L. P., Nabais, C., Tomé, A. R., Freitas, H., Geraldes, C. F., et al. (2004). Effects of $\mathrm{Li}^{+}$transport and intracellular binding on $\mathrm{Li}^{+} / \mathrm{Mg}^{2+}$ competition in bovine chromaffin cells. Biochim. Biophys. Acta, 1691 79-90. doi: 10.1016/j.bbamcr.2003.12.005

Förstermann, U., and Münzel, T. (2006). Endothelial nitric oxide synthase in vascular disease: from marvel to menace. Circulation 113, 1708-1714. doi: 10.1161/CIRCULATIONAHA.105.602532

Gao, L., Smieleweski, P., Czosnyka, M., and Ercole, A. (2016). Cerebrovascular signal complexity six hours after intensive care unit admission correlates with outcome after severe traumatic brain injury. J. Neurotrauma 33, 2011-2018. doi: 10.1089/neu.2015.4228

Garcia, J. G., Davis, H. W., and Patterson, C. E. (1995). Regulation of endothelial cell gap formation and barrier dysfunction: role of myosin light chain phosphorylation. J. Cell. Physiol. 163, 510-522. doi: 10.1002/jcp.1041 630311

Geddes, J. R., and Miklowitz, D. J. (2013). Treatment of bipolar disorder. Lancet 381, 1672-1682. doi: 10.1016/S0140-6736(13)60857-0

Gold, A. B., Herrmann, N., and Lanctot, K. L. (2011). Lithium and its neuroprotective and neurotrophic effects: potential treatment for post-ischemic stroke sequelae. Curr. Drug Targets 12, 243-255. doi: 10.2174/138945011794 182764

Gould, T. D., and Manji, H. K. (2005). Glycogen synthase kinase-3: a putative molecular target for lithium mimetic drugs. Neuropsychopharmacology 30, 1223-1237. doi: 10.1038/sj.npp.1300731

Grove, T., Taylor, S., Dalack, G., and Ellingrod, V. (2015). Endothelial function, folate pharmacogenomics, and neurocognition in psychotic disorders Schizophr. Res. 164, 115-121. doi: 10.1016/j.schres.2015.02.006

Gündüz, D., Hirche, F., Härtel, F. V., Rodewald, C. W., Schäfer, M., Pfitzer, G., et al. (2003). ATP antagonism of thrombin-induced endothelial barrier permeability. Cardiovasc. Res. 59, 470-478. doi: 10.1016/S0008-6363(03)00427-9

Gündüz, D., Klewer, M., Bauer, P., Tanislav, C., Sedding, D., Rohrbach, S., et al. (2015). Compound C inhibits in vitro angiogenesis and ameliorates 
thrombin-induced endothelial barrier failure. Eur. J. Pharmacol. 768, 165-172. doi: 10.1016/j.ejphar.2015.10.048

Hacke, W., Schwab, S., Horn, M., Spranger, M., De Georgia, M., and von Kummer, R. (1996). 'Malignant' middle cerebral artery territory infarction: clinical course and prognostic signs. Arch. Neurol. 53, 309-315. doi: 10.1001/archneur.1996.00550040037012

Heiss, W. D., Graf, R., and Wienhard, K. (2001). Relevance of experimental ischemia in cats for stroke management: a comparative reevaluation. Cerebrovasc. Dis. 11, 73-81. doi: 10.1159/000047616

Helbok, R., Schiefecker, A. J., Friberg, C., Beer, R., Kofler, M., Rhomberg, P., et al. (2016). Spreading depolarizations in patients with spontaneous intracerebral hemorrhage: association with perihematomal edema progression. J. Cereb. Blood Flow Metab. doi: 10.1177/0271678X16651269. [Epub ahead of print].

Helms, H. C., Abbott, N. J., Burek, M., Cecchelli, R., Couraud, P.-O., Deli, M. A., et al. (2016). In vitro models of the blood-brain barrier: an overview of commonly used brain endothelial cell culture models and guidelines for their use. J. Cereb. Blood Flow Metab. 36, 862-890. doi: 10.1177/0271678X16630991

Koerselman, J., van der Graaf, Y., de Jaegere, P. P., and Grobbee, D. E. (2003). Coronary collaterals: an important and underexposed aspect of coronary artery disease. Circulation 107, 2507-2511. doi: 10.1161/01.CIR.0000065118. 99409.5F

Kopaliani, I., Martin, M., Zatschler, B., Bortlik, K., Müller, B., and Deussen, A. (2014). Cell-specific and endothelium-dependent regulations of matrix metalloproteinase-2 in rat aorta. Basic Res. Cardiol. 109, 419. doi: 10.1007/s00395-014-0419-8

Lan, C. C., Liu, C. C., Lin, C. H., Lan, T. Y., McInnis, M. G., Chan, C. H., et al. (2015). A reduced risk of stroke with lithium exposure in bipolar disorder: a population-based retrospective cohort study. Bipolar Disord. 17, 705-714. doi: $10.1111 /$ bdi.12336

Leeds, P. R., Yu, F., Wang, Z., Chiu, C. T., Zhang, Y., Leng, Y., et al. (2014). A new avenue for lithium: intervention in traumatic brain injury. ACS Chem. Neurosci. 5, 422-433. doi: $10.1021 / \mathrm{cn} 500040 \mathrm{~g}$

Macdonald, R. L. (2014). Delayed neurological deterioration after subarachnoid haemorrhage. Nat. Rev. Neurol. 10, 44-58. doi: 10.1038/nrneurol.2013.246

Meier, P., Schirmer, S. H., Lansky, A. J., Timmis, A., Pitt, B., and Seiler, C. (2013). The collateral circulation of the heart. BMC Med. 11:143. doi: 10.1186/1741-7015-11-143

Meisel, A., Meisel, C., Harms, H., Hartmann, O., and Ulm, L. (2012). Predicting post-stroke infections and outcome with blood-based immune and stress markers. Cerebrovasc. Dis. 33, 580-588. doi: 10.1159/000338080

Mohammad, O., and Osser, D. N. (2014). The psychopharmacology algorithmproject at the Harvard South Shore Program: an algorithm for acute mania. Harv. Rev. Psychiatry 22, 274-294. doi: 10.1097/HRP.0000000000 000018

Mohammadianinejad, S. E., Majdinasab, N., Sajedi, S. A., Abdollahi, F., Moqaddam, M. M., and Sadr, F. (2014). The effect of lithium in poststroke motor recovery: a double-blind, placebo-controlled, randomized clinical trial. Clin. Neuropharmacol. 37, 73-78. doi: 10.1097/WNF.0000000000 000028

Mulvany, M. J., and Halpern, W. (1977). Contractile properties of small arterial resistance vessels in spontaneously hypertensive and normotensive rats. Circ. Res. 41, 19-26. doi: 10.1161/01.RES.41.1.19

Munaron, L., and Fiorio Pla, A. (2009). Endothelial calcium machinery and angiogenesis: understanding physiology to interfere with pathology. Curr. Med. Chem. 16, 4691-4703. doi: 10.2174/092986709789878210

Noll, T., Hölschermann, H., Koprek, K., Gündüz, D., Haberbosch, W., Tillmanns, H., et al. (1999). ATP reduces macromolecule permeability of endothelial monolayers despite increasing $\left[\mathrm{Ca}^{2+}\right]_{\mathrm{i}}$. Am. J. Physiol. 276, H1892-H1901.

Rahimzadeh-Rofouyi, B., Afsharimani, B., Moezi, L., Ebrahimi, F., Mehr, S. E., Mombeini, T., et al. (2007). Role of nitric oxide and prostaglandin systems in lithium modulation of acetylcholine vasodilation. J. Cardiovasc. Pharmacol. 50, 641-646. doi: 10.1097/FJC.0b013e318153f262

Rajkowska, G. (2000). Postmortem studies in mood disorders indicate altered numbers of neurons and glial cells. Biol. Psychiatry 48, 766-777. doi: 10.1016/S0006-3223(00)00950-1

Renú, A., Amaro, S., Laredo, C., Román, L. S., Llull, L., Lopez, A., et al. (2015). Relevance of blood-brain barrier disruption after endovascular treatment of ischemic stroke: dual-energy computed tomographic study. Stroke 46, 673-679. doi: 10.1161/STROKEAHA.114.008147
Ryglewski, S., Pflueger, H. J., and Duch, C. (2007). Expanding the neuron's calcium signaling repertoire: intracellular calcium release via voltage-induced PLC and IP3R activation. PLoS Biol. 5:e66. doi: 10.1371/journal.pbio.0050066

Schäfer, M., Bahde, D., Bosche, B., Ladilov, Y., Schäfer, C., Piper, H. M., et al. (2001). Modulation of early $\left[\mathrm{Ca}^{2+}\right]_{\mathrm{i}}$ rise in metabolically inhibited endothelial cells by xestospongin C. Am. J. Physiol. Heart Circ. Physiol. 280, H1002-H1010.

Stokum, J. A., Gerzanich, V., and Simard, J. M. (2016). Molecular pathophysiology of cerebral edema. J. Cereb. Blood Flow Metab. 36, 513-538. doi: $10.1177 / 0271678 X 15617172$

Trepiccione, F., and Christensen, B. M. (2010). Lithium-induced nephrogenic diabetes insipidus: new clinical and experimental findings. J. Nephrol. 23, $43-48$.

Urday, S., Kimberly, W. T., Beslow, L. A., Vortmeyer, A. O., Selim, M. H., Rosand, J., et al. (2015). Targeting secondary injury in intracerebral haemorrhage-perihaematomal oedema. Nat. Rev. Neurol. 11, 111-122. doi: $10.1038 /$ nrneurol.2014.264

van den Wijngaard, I. R., Holswilder, G., Wermer, M. J., Boiten, J., Algra, A., Dippel, D. W., et al. (2016). Assessment of collateral status by dynamic CT angiography in acute MCA stroke: timing of acquisition and relationship with final infarct volume. Am. J. Neuroradiol. 37, 1231-1236. doi: 10.3174/ajnr.A4746

van der Hoeven, E. J. R. J., McVerry, F., Vos, J. A., Algra, A., Puetz, V., Kappelle, L. J., et al. (2016). Collateral flow predicts outcome after basilar artery occlusion: the posterior circulation collateral score. Int. J. Stroke 11, 768-775. doi: 10.1177/1747493016641951

Vo, T. M., Perry, P., Ellerby, M., and Bohnert, K. (2015). Is lithium a neuroprotective agent? Ann. Clin. Psychiatry 27, 49-54.

Volny, O., Cimflova, P., and Mikulik, R. (2016). Ipsilateral sinus hypoplasia and poor leptomeningeal collaterals as midline shift predictors. J. Stroke Cerebrovasc. Dis. 25, 1792-1796. doi: 10.1016/j.jstrokecerebrovasdis.2016.04.004

Vosahlikova, M., and Svoboda, P. (2016). Lithium - therapeutic tool endowed with multiple beneficiary effects caused by multiple mechanisms. Acta Neurobiol. Exp. (Wars). 76, 1-19.

Wijdicks, E. F., Sheth, K. N., Carter, B. S., Greer, D. M., Kasner, S. E., Kimberly, W. T., et al. (2014). American heart association stroke council. Recommendations for the management of cerebral and cerebellar infarction with swelling: a statement for healthcare professionals from the American Heart Association/American Stroke Association. Stroke 45, 1222-1238. doi: 10.1161/01.str.0000441965.15164.d6

Wilbring, M., Tugtekin, S. M., Zatschler, B., Ebner, A., Reichenspurner, H., Kappert, U., et al. (2013). Preservation of endothelial vascular function of saphenous vein grafts after long-time storage with a recently developed potassium-chloride and $\mathrm{N}$-acetylhistidine enriched storage solution. Thorac. Cardiovasc. Surg. 61, 656-662. doi: 10.1055/s-0032-1311549

Yatham, L. N., Kennedy, S. H., Parikh, S. V., Schaffer, A., Beaulieu, S., Alda, M., et al. (2013). Canadian Network for Mood and Anxiety Treatments (CANMAT) and International Society for Bipolar Disorders (ISBD) collaborative update of CANMAT guidelines for the management of patients with bipolar disorder: update 2013. Bipolar Disord. 15, 1-44. doi: 10.1111/bdi.12025

Yoo, S. Y., and Kim, J. Y. (2009). Recent insights into the mechanisms of vasospastic angina. Korean Circ. J. 39, 505-511. doi: 10.4070/kcj.2009.39.12.505

Conflict of Interest Statement: BB got a travel grant and a speaker honorary from CSL Behring, Germany. RM is chief scientific officer of Edge Therapeutics, Inc. BB is a member of the scientific advisory board of Edge Therapeutics. BB, RM, and TN got material support of CSL Behring, Germany, and Canada. MO received travel support, and/or speaker honoraria from Biogen Idec, Novartis, Sanofi-Aventis, Genzyme, Pfizer, Teva, and Heel. The other authors declare that the research was conducted in the absence of any commercial or financial relationships that could be construed as a potential conflict of interest.

Copyright () 2016 Bosche, Molcanyi, Rej, Doeppner, Obermann, Müller, Das, Hescheler, Macdonald, Noll and Härtel. This is an open-access article distributed under the terms of the Creative Commons Attribution License (CC BY). The use, distribution or reproduction in other forums is permitted, provided the original author(s) or licensor are credited and that the original publication in this journal is cited, in accordance with accepted academic practice. No use, distribution or reproduction is permitted which does not comply with these terms. 